\title{
Regional climate feedback of anthropogenic aerosols over Europe using RegCM3
}

\author{
P. Zanis ${ }^{1, *}$, C. Ntogras ${ }^{1}$, A. Zakey ${ }^{2}$, I. Pytharoulis ${ }^{1}$, T. Karacostas ${ }^{1}$ \\ ${ }^{1}$ Department of Meteorology and Climatology, School of Geology, Aristotle University of Thessaloniki, Thessaloniki 54124, \\ Greece \\ ${ }^{2}$ Earth System Physics Section, The Abdus Salam International Centre for Theoretical Physics (ICTP), 34100 Trieste, Italy
}

\begin{abstract}
The regional climate model RegCM3 coupled with aerosols is used in this study to investigate the direct shortwave effect of anthropogenic aerosols on the regional European climate over a 12 yr period (1996-2007). Aerosol feedback induced small changes in the yearly averaged near-surface temperature over Europe during this period and the greatest negative temperature difference of $-0.2^{\circ} \mathrm{C}$ was observed over the Balkan Peninsula. The field of aerosol-induced near-surface temperature anomalies is not spatially collocated with the field of aerosol radiative forcing as the spatial correlation coefficient is only 0.24 . A characteristic of the aerosol-induced changes on near-surface temperature is a dipole pattern in which cooling occurs south of the latitudinal zone from 50 to $55^{\circ} \mathrm{N}$ and warming occurs northwards. This characteristic dipole pattern of changes in temperature is also seen at higher atmospheric levels but the signal weakens at higher altitudes. A characteristic in the aerosol-induced changes in atmospheric circulation is a negative anomaly of the zonal westerly wind of $500 \mathrm{hPa}$ in the latitudinal belt between 45 and $55^{\circ} \mathrm{N}$, which is consistent with a dipole pattern in geopotential heights that consists of an anticyclonic anomaly north of approx. $55^{\circ} \mathrm{N}$ and cyclonic anomaly south of approx. $45^{\circ} \mathrm{N}$. The greatest aerosol-induced negative lower troposphere temperature anomaly over the Balkan Peninsula is associated with the collocated greatest cyclonic anomaly. This reveals the important role of the aerosol-induced circulation changes for the pattern of the temperature anomalies and explains the poor correlation between the patterns of aerosol-induced temperature changes and aerosol radiative forcing. Because the aerosol-induced changes in temperature and atmospheric circulation are at the limits of statistical significance, the present regional climate modelling study indicates there is a limited feedback on the European climate related to the direct shortwave effect of European anthropogenic aerosols.
\end{abstract}

KEY WORDS: Aerosols · Climate feedback · Direct effect · Regional climate models · Simulations · Europe Resale or republication not permitted without written consent of the publisher

\section{INTRODUCTION}

Aerosols enhance scattering and absorption of solar radiation (direct effect and semi-direct effect) and also produce brighter clouds (first indirect effect) and longer cloud lifetime (second indirect effect) and thus strongly affect Earth's climate (Hansen et al. 1997, Lohmann \& Feichter 2001, Ramanathan et al. 2001). Aerosols of anthropogenic origin are mainly composed of sulphates, carbonaceous particles (black carbon and organic carbon), nitrates, ammonium and mineral dust of industrial origin (Ghan \& Schwartz 2007). Generally the direct and indirect effects of anthropogenic aerosols lead to reductions in the amount of solar radiation reaching Earth's surface, thus causing a negative radiative forcing (IPCC 2007). However, the radiative forcing of absorbing aerosols (like black carbon) can be also positive 
through their semi-direct effect (Menon et al. 2002), especially when the absorbing aerosols are located within the atmospheric boundary layer (Johnson et al. 2004). Atmospheric aerosols are still considered one of the main sources of uncertainty in the climate change debate (IPCC 2007).

To study the climate feedback of aerosols it is necessary to couple climate and chemistry/aerosol models. The interactive coupling of complex climate models and full chemistry schemes is still computationally too demanding and alternatively simplified chemistry modules have been developed to allow chemistry-climate studies. This approach has been mainly applied to global models (e.g. Chung \& Seinfeld 2002, Reddy \& Boucher 2004). However, the relatively short lifetime of aerosols, in the order of a few days, and their spatial inhomogeneity determined by local sources indicates the importance of regional scale when studying aerosol effects. Also, the aerosols' radiative forcing at regional scales can be much larger than that of the 20th century rise in the greenhouse gas concentrations (Ramanathan et al. 2001). Furthermore, the aerosol-induced changes in the Earth's radiation budget can have strong effects on a regional scale, causing changes in atmospheric thermal structure, changes in synoptic and regional circulation systems, suppression of rainfall and less efficient removal of pollutants (Ramanathan \& Feng 2009). The current knowledge concerning the effects of aerosol particles on the state of the atmosphere is limited on a regional scale (Bäumer \& Vogel 2007).

The above-mentioned facts point to the need for applying a similar coupling approach in regional climate models (RCMs) (Solmon et al. 2006). Giorgi et al. $(2002,2003)$ and Qian et al. $(2001,2003)$ followed such a regional coupled climate-chemistry/aerosol model approach and found that the direct and indirect effects on the regional climate caused by anthropogenic aerosols over East Asia partially explained the cooling trend observed over various regions of China during the last decades of the 20th century. Ekman \& Rodhe (2003) used a regional atmospheric climate model with an interactive module of the tropospheric sulphur cycle to study the effect of model resolution on the regional temperature response due to the indirect effect of anthropogenic sulphate aerosols on cloud albedo over Europe.

Solmon et al. (2006) implemented a simplified anthropogenic aerosol model within the regional climate model RegCM for use in climate studies. After evaluation of the model performance with measured surface concentrations and aerosol optical depths (AODs), and despite the deficiencies identified, Sol- mon et al. (2006) concluded that the model shows a performance in line with that of other coupled climate/aerosol models and can presently provide a useful tool for sensitivity and process studies. Zanis (2009) used this model setup to investigate the direct shortwave effect of anthropogenic aerosols on the near-surface temperature over southeastern Europe during summer in 2000 and found that the aerosolinduced changes in the circulation indicated a southward shift of the subtropical jet stream. Huszar et al. (2012) coupled RegCM3 with the air quality model CAMx to investigate the climate feedbacks of ozone and aerosols and found that the aerosol climate feedback in this coupled version of RegCM3/CAMx was similar to that in the RegCM3/aerosol model used in the present study.

Recently, more complex aerosol schemes have been also implemented in limited-area models for regional climate studies over Europe. Vogel et al. (2009) applied the comprehensive model system COSMO-ART for 2 cases studies, one characterized by almost cloud-free conditions and the second one by cloudy conditions, to study the radiative feedback of aerosols on the state of the atmosphere on a regional scale. Zubler et al. (2011a) evaluated a new aerosol modelling framework that accounted for the microphysical interactions of internally and externally mixed aerosol particles and conducted RCM simulations with the COSMO-CLM limited-area model at a horizontal resolution of $50 \mathrm{~km}$ for Europe over the period 1997-2003. They found that the new scheme more realistically reproduced the annual mean pattern of the AOD derived from satellite data over Europe. Furthermore, Zubler et al. (2011b) used the above-mentioned modelling framework to carry out 2 ERA-40 driven simulations from 1958 to 2001 to simulate dimming and brightening in Europe: the first simulation with constant climatological emissions and the second one with transient aerosol emissions.

The present work investigated the direct shortwave effect of anthropogenic aerosols on the nearsurface temperatures over Europe based on simulations performed by the regional climate model RegCM3 coupled with a simplified aerosol model for the period 1996-2007.

\section{DATA AND EXPERIMENTAL SETUP}

The RegCM3, obtained on-line, coupled with aerosol modules was used to investigate the aerosol feedback to climate (Solmon et al. 2006). RegCM3 is a 3-dimensional (3D), sigma-coordinate, primitive equa- 
tion RCM that was originally developed at the National Center for Atmospheric Research (NCAR) and has been mostly applied to studies of regional climate and seasonal predictability around the world (Giorgi et al. 2006, Pal et al. 2007). The dynamical core is based on the hydrostatic version of the NCARPSU Mesoscale Model v. 5 (MM5) (Grell et al. 1994). The radiative transfer package is taken from the Community Climate Model v. 3 (CCM3) (Kiehl et al. 1996). The large-scale cloud and precipitation computations are performed by Subgrid Explicit Moisture Scheme (SUBEX, Pal et al. 2000) and the land surface physics are according to the BiosphereAtmosphere Transfer Scheme (BATS, Dickinson et al. 1993). The adopted convective scheme for the RCM simulations in the present study is the Grell scheme (Grell 1993) with the Fritsch \& Chappell (1980) closure assumption. There are a number of previous studies that evaluated the model performance of RegCM3 around the world (Pal et al. 2007 and references therein). Recent studies based on an ensemble of RCM simulations over Europe showed good performance of RegCM3 in terms of reproducing weather regimes (Sanchez-Gomez et al. 2009), spatial patterns and amounts of precipitation (Rauscher et al. 2010).

The coupled version of the RegCM3/aerosol model used in this study takes into account only the direct shortwave effects of anthropogenic aerosols. The aerosol model includes sulphur dioxide $\left(\mathrm{SO}_{2}\right)$, sulphate $\left(\mathrm{SO}_{4}{ }^{2-}\right)$ and hydrophobic and hydrophilic carbonaceous particles such as black carbon (BC) and organic carbon (OC). Hence, a total of 6 tracers are taken into account by the aerosol model. For each tracer the corresponding mass-mixing ratio is calculated by using the tracer transport equation, which includes advection, horizontal and vertical turbulent diffusion and convective transport, wet removal and dry deposition as well as production and losses due to physico-chemical transformations (Qian et al. 2001). Following Kasibhatla et al. (1997), the convectivetransport term assumes that the tracer becomes well mixed between cloud base and cloud top when cumulus convection occurs. The wet removal is the function of the rate of conversion of cloud water to rainwater, the grid cell cloud fraction and the fraction of tracer dissolved into cloud water. Dry deposition is treated in a simplified way by assuming fixed deposition velocities over land and water for each tracer. For the sulphur compounds, the conversion of $\mathrm{SO}_{2}$ to $\mathrm{SO}_{4}{ }^{2-}$ occurs through both aqueous and gas phase oxidation pathways. Following Cooke et al. (1999), the ageing process of carbonaceous aerosol is simply represented by a transfer from the hydrophobic to the hydrophilic state with an exponential lifetime of $1.15 \mathrm{~d}$. Aerosol concentrations are fixed to zero at the domain boundaries, assuming that external incoming aerosol amount is small compared with the sources.

The AOD for a given spectral interval is calculated from the aerosol concentration and extinction coefficient depending on the refractive index and the particle size distribution. The hygroscopic growth of hydrophilic aerosols and its influence on optical properties is taken into account. For sulphate, the parametrization of Kiehl et al. (2000) is used. For carbonaceous aerosol, the hygroscopic growth effect on the extinction coefficient is formulated as in Kasten (1969). Dry values of the extinction coefficient are calculated by using a Mie code (Mätzler 2002) assuming refractive indices and lognormal size distributions. A detailed description of the aerosol model can be found at Solmon et al. (2006).

Data on anthropogenic emissions of $\mathrm{SO}_{2}$ are provided by the public release of the Emission Database for Global Atmospheric Research (EDGAR) global data base in $1^{\circ}$ resolution over the globe. The calculation of fossil fuel emissions for BC and OC particles is based on the Cooke et al. (2002) methodology and it accounts for different types of fuel combustions and emission factors. The inventory for BC and OC is also provided in $1^{\circ}$ resolution over the globe. The emission inventories adopted for the present study are representative for the year 2000.

An evaluation study of the RegCM3/aerosol model that used ground-based measurements of $\mathrm{SO}_{2}$ from the EMEP (European Monitoring and Evaluation Programme) European network as well as AOD measurements from ground-based and satellite platforms revealed a consistent reproduction of the observed spatial patterns by the model (Solmon et al. 2006). Specifically, a comparison with available Aerosol Robotic Network (AERONET) AOD values from groundbased remote sensing instruments revealed a satisfactory agreement within a factor of 1.5 between simulated and observed AOD values over northern Europe in the visible and UV range for both summer and winter seasons of the year 2000. Furthermore a comparison with the AOD values from satellite platforms with the Moderate Resolution Imaging Spectroradiometer (MODIS) instrument indicated that the position of AOD maxima is consistent between RegCM and MODIS results (Solmon et al. 2006).

In the present study RegCM3/aerosol simulations were performed over a European domain shown in Fig. 1 with a grid resolution of $50 \times 50 \mathrm{~km}$ (18 layers up to $50 \mathrm{hPa}$ ) forced by the NCEP-DOE AMIP-II reanaly- 


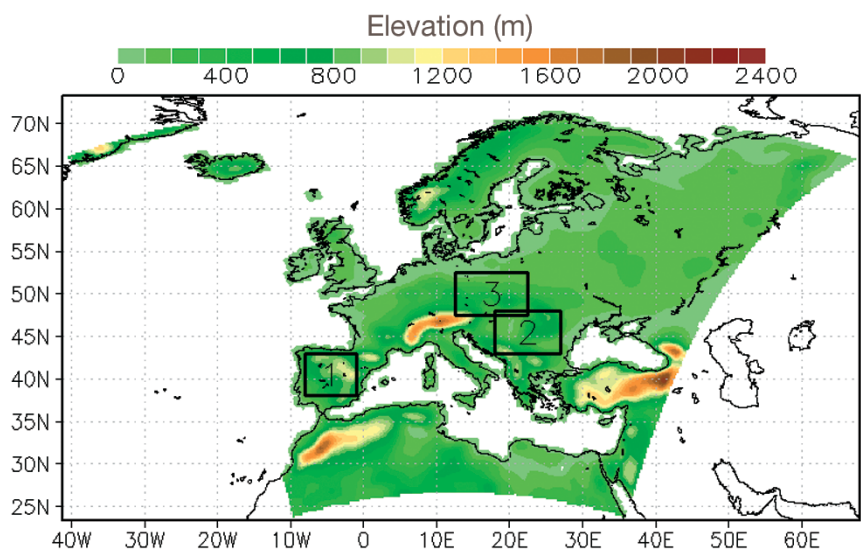

Fig. 1. Topography of the European domain with a grid resolution $50 \times 50 \mathrm{~km}$. Black boxes indicate 3 regions in Europe: (a) Region 1 in southwestern Europe (SWE), (b) Region 2 in southeastern Europe (SEE) and (c) Region 3 in centraleastern Europe (CEE)

sis data set (Kanamitsu et al. 2002) for 1996 to 2007. The sea surface temperature (SST) was constrained in our simulations by NOAA optimum interpolation (OI) SST weakly means with a spatial coverage of $1.0^{\circ} \times$ $1.0^{\circ}$ (www.esrl.noaa.gov/psd/data/gridded/data.noaa. oisst.v2.html). To investigate the effect of anthropogenic aerosol loading on air temperature and atmospheric circulation patterns, 2 sets of 12 yr simulations were performed: the control run $\left(\mathrm{C}_{\text {run }}\right)$ in which the chemical tracers were only transported and had no feedback in the radiative scheme, and one run that included the direct aerosol feedback on the shortwave radiation $\left(\mathrm{AF}_{\text {run }}\right)$. Even though the direct effect of aerosols in longwave is not taken into account in our simulations, this is not a limitation for anthropogenic aerosols. This is because the longwave direct radiative forcing is only substantial if the aerosol particles are large (such as dust or sea salt) and occur in considerable concentrations at higher altitudes, while this process is not significant for the smaller anthropogenic aerosols (IPCC 2007, Ramanathan \& Feng 2009).

\section{RESULTS}

\subsection{Aerosol optical depth and the associated radiative forcing}

The simulated annual mean field of the AOD at the visible $(550 \mathrm{~nm})$ wavelength indicated that higher values in central Europe extended from the centralwestern to central-eastern regions (Fig. 2a). This spatial distribution of the AOD is mainly associated with the spatial distribution of the emission sources of the anthropogenic sulphate and carbonaceous aerosols (e.g. see Fig. 2 in Zanis 2009) and their dispersion with the mean flow. The annual averages of simulated AOD for the whole domain and 3 selected regions in Europe are shown in Table 1 and are indicated by black boxes in Fig. 1. For comparison purposes Table 1 also shows the respective annual averages of AOD values (within parentheses) based on MODIS Terra and Aqua monthly Level-3 satellite data (collection 5.1) from 2000 to 2007 (http://gdata1. sci.gsfc.nasa.gov/daac-bin/G3/). Recent studies show that MODIS C005 data are validated and quantitative and despite their uncertainties compare relatively well with station data from the AERONET network over land, especially over Europe (Papadimas et al. 2009, Levy et al. 2010). For example, Levy et al. (2010) found that $>66 \%$ of MODIS-retrieved AOD values compare with AERONET observed values within an expected error envelope of $\pm(0.05+15 \%)$, with high correlation $(\mathrm{R}=0.9)$. Papadimas et al. (2009) reported small differences between MODIS C005 and the AERONET AOD values over the greater
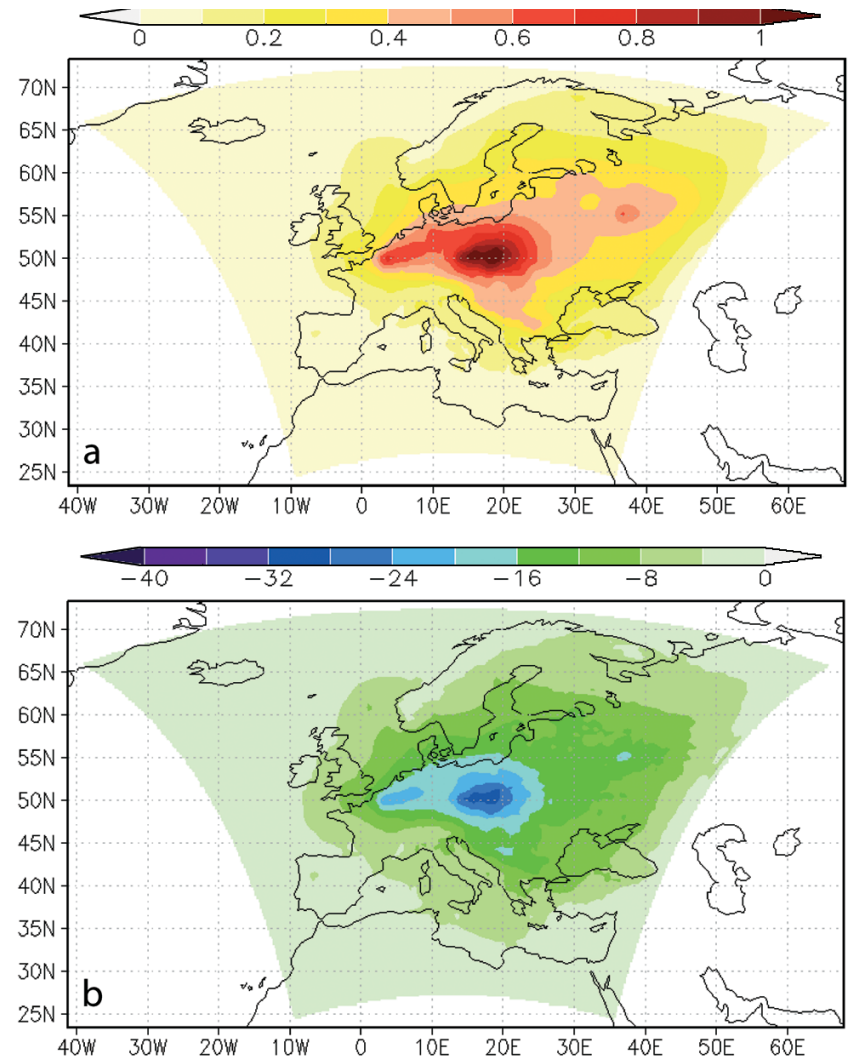

Fig. 2. Annual mean field of the (a) aerosol optical depth (AOD) and (b) radiative forcing at the top of the atmosphere $\left(\mathrm{RF}_{\mathrm{TOA}}\right)$ from 1996 to 2007 due to anthropogenic aerosols obtained from the RegCM3/aerosol simulations 
Table 1. Annual averages of simulated aerosol optical depth (AOD) and radiative forcing at the top of the atmosphere $\left(\mathrm{RF}_{\mathrm{TOA}}\right)$ from RegCM3 for the whole domain and 3 selected regions in Europe: (a) Region 1 in southwestern Europe (SWE), (b) Region 2 in southeastern Europe (SEE) and (c) Region 3 in central-eastern Europe (CEE). The values within parentheses denote annual averages of AOD based on MODIS Terra and Aqua monthly Level-3 satellite data from 2000 to 2007 (http://gdata1.sci.gsfc.nasa.gov/daac-bin/G3/ gui.cgi?instance_id=MODIS_MONTHLY_L3)

\begin{tabular}{|lcc|}
\hline Region & $\mathrm{AOD}$ & $\mathrm{RF}_{\mathrm{TOA}}\left(\mathrm{W} \mathrm{m}^{-2}\right)$ \\
\hline Whole domain & $0.18(0.16)$ & -6.6 \\
Region 1: SWE & $0.07(0.11)$ & -3 \\
Region 2: SEE & $0.48(0.17)$ & -14.3 \\
Region 3: CEE & $0.80(0.19)$ & -23.4 \\
\hline
\end{tabular}

Mediterranean basin for which the mean AOD value for MODIS C005 was $0.23 \pm 0.19$ (mean \pm SD) and for AERONET was $0.23 \pm 0.17$.

In the present study, the AOD annual average from the RegCM3 simulations for the whole domain is similar to that of MODIS AOD, but simulated AOD values are overestimated for central-eastern Europe (Region 3) where the maximum emissions are located, as well for southeastern Europe (Region 2). In southwestern Europe above the Iberian Peninsula (Region 1) the simulated AOD value is underestimated compared with that of MODIS, but this is reasonable as natural aerosols and dust particles are not considered in our RegCM3 simulations. However, these comparisons between MODIS and RegCM3 AOD should not be considered as an attempt to evaluate the models since only anthropogenic sulphate and carbonaceous aerosols were included in our RegCM3 simulations. This work was focused on the regional climate sensitivity to European anthropogenic aerosols. The comparison between MODIS and RegCM3 AOD aims to show the degree of agreement between the real and simulated aerosol loading and the associated magnitude of the aerosol radiative disturbance implemented in our simulations.

The derived annual radiative forcing at the top of the atmosphere $\left(\mathrm{RF}_{\mathrm{TOA}}\right)$ field associated with the anthropogenic aerosol loading shown in Fig. 2a is illustrated in Fig. 2b. The $\mathrm{RF}_{\mathrm{TOA}}$ is negative (as expected owing to the solar dimming effect of anthropogenic aerosols) throughout the European domain with the more negative $\mathrm{RF}_{\mathrm{TOA}}$ values in central and central-eastern Europe (between $48^{\circ}$ and $55^{\circ} \mathrm{N}$ ) where the highest anthropogenic aerosol loading is attained. A visual inspection of Fig. 2a,b indicates a spatial correlation between the AOD and $\mathrm{RF}_{\mathrm{TOA}}$ fields. Annual averages of simulated $\mathrm{RF}_{\mathrm{TOA}}$ for the whole do- main and 3 selected regions in Europe are shown in Table 1. For our whole European domain the average $\mathrm{RF}_{\mathrm{TOA}}$ was $-6.6 \mathrm{~W} \mathrm{~m}^{-2}$ for a respective AOD value of 0.18, while for central-eastern Europe the average was $-23.6 \mathrm{~W} \mathrm{~m}^{-2}$ for a respective AOD value of 0.80 .

The overestimation of simulated AOD with respect to MODIS, especially in central-eastern Europe where the maximum emissions are located, implies there is an overestimated anthropogenic aerosol loading and aerosol forcing in our results. Nevertheless, our simulated $\mathrm{AOD}$ and $\mathrm{RF}_{\mathrm{TOA}}$ values over central-eastern Europe are within the range of other previous modelling studies. For example, in Takemura et al. (2002) the AOD values in central Europe ranged from 0.5 to 1 throughout the year with annual radiative forcing values that ranged from -1 to $-10 \mathrm{~W} \mathrm{~m}^{-2}$ at the tropopause over Europe due to sulphate aerosols under clear sky conditions, while the annual mean value was estimated to reach $-3 \mathrm{~W} \mathrm{~m}^{-2}$ over industrial regions of the Northern Hemisphere. Jacobson (2001) reported annual averaged AOD values over Europe from 0.1 to 0.6 , and yearly averaged all-sky tropopause direct forcing that ranged from -1 to $-5 \mathrm{~W}$ $\mathrm{m}^{-2}$ was due to anthropogenic sulphate aerosols. For their whole European domain, Ekman \& Rodhe (2003) calculated an annual mean difference in shortwave radiation at the top of the atmosphere between the feedback and reference simulation of $-2.7 \mathrm{~W} \mathrm{~m}^{-2}$. In eastern Asia, Giorgi et al. (2002) reported that anthropogenic sulphate induced a negative radiative forcing at the top of the atmosphere showing values that varied spatially from -1 to $-8 \mathrm{~W} \mathrm{~m}^{-2}$ in winter to -1 to $-15 \mathrm{~W} \mathrm{~m}^{-2}$ in summer, and the AOD values ranged from 0.15 to 0.70 (Qian et al. 2001). Li et al. (2004) calculated $\mathrm{RF}_{\mathrm{TOA}}$ values of $-35 \mathrm{~W} \mathrm{~m}^{-2}$ due to Saharan dust aerosols and AOD values between 0.8 and 1, which are consistent with their observations.

The columnar single scattering albedo (SSA) values in our simulations >0.99 for the whole domain. However, these simulated SSA values are greater than those from other recent studies over Europe. For example, Tombette et al. (2008), who carried out a detailed comparison of aerosol optical properties over Europe based on measurements from the AERONET network and simulations from a 3D size-resolved aerosol model, found columnar SSA values ranging from 0.91 to 0.97 at $550 \mathrm{~nm}$. Similarly Takemura et al. (2002) simulated SSA values with a global 3D model that ranged from 0.90 to 0.98 at $550 \mathrm{~nm}$ over Europe throughout the year. Our SSA values indicated the dominating scattering role of sulphate aerosols in our simulations. This has an implication for the interpretation of the results concerning the direct aerosol effect 
on near-surface temperature as previous studies have clearly shown that the atmospheric boundary layer cooling effect is highest for the non-absorbing aerosols. For example, Yu et al. (2002) investigated the radiative effects of aerosols in the atmospheric boundary layer (ABL) by using a 1D ABL model and calculated that the changes of air temperature at $2 \mathrm{~m}$ due to purely scattering aerosols $(\mathrm{SSA}=1)$ at noon ranged from $-1^{\circ} \mathrm{C}$ for an AOD of approx. 0.3 to $-3^{\circ} \mathrm{C}$ for an AOD value of approx. 0.9. By assuming an SSA of 0.9 this model resulted in small positive changes of near-surface temperatures, which become even more positive for strongly absorbed aerosols ( $\mathrm{SSA}=0.8$ ).
This dipole pattern of aerosol feedback on $T 2 \mathrm{~m}$ remains in the lower and middle troposphere as is illustrated in Fig. 4 from the yearly averaged mean fields of the difference between $\mathrm{AF}_{\text {run }}$ and $\mathrm{C}_{\text {run }}$ in air temperature at $850 \mathrm{hPa}(T 850)$ and $500 \mathrm{hPa}(T 500)$. However, the signal of aerosol-induced temperature changes weakens upwards while the areas with statistically significant changes at the $90 \%$ confidence level are also reduced upwards. Thus, the aerosolinduced changes in T850 range between 0.1 and $-0.1^{\circ} \mathrm{C}$, while in $T 500$ the changes range between 0.06 and $-0.06^{\circ} \mathrm{C}$. The dipole pattern structure in temperature and the absence of spatial correlation with the aerosol radiative forcing indicate the com-

\subsection{Aerosol feedback on temperature and circulation}

The yearly averaged aerosol-induced changes on near-surface air temperature at $2 \mathrm{~m}(T 2 \mathrm{~m})$ from 1996 to 2007 is illustrated in Fig. 3a. Overall, in the largest part of Europe there was a tendency for slight cooling that ranged between -0.1 and $-0.2^{\circ} \mathrm{C}$, and the greatest negative $T 2 \mathrm{~m}$ differences were observed over the Balkan Peninsula. This slight cooling is statistically significant at the $90 \%$ confidence level according to a 2-tailed paired $t$-test for the largest part of Europe. The aerosol-induced decrease of $T 2 \mathrm{~m}$ over this part of Europe is in accordance with a decrease of the surface radiation budget (all-sky shortwave solar radiation absorbed and longwave terrestrial radiation emitted) shown in Fig. 3b. Interestingly, there is a slight warming up to $0.1^{\circ} \mathrm{C}$ north of $55^{\circ} \mathrm{N}$ (Fig. 3a) over Scandinavia and northern Russia, mainly over Finland, which is statistically significant. This dipole pattern of aerosol-induced changes on $T 2 \mathrm{~m}$ in conjunction with cooling south of the latitudinal zone 50 to $55^{\circ} \mathrm{N}$ and warming north of $55^{\circ} \mathrm{N}$ is shown in Fig. 3a.

Another interesting point is related to the spatial correspondence between the fields of the aerosol $\mathrm{RF}_{\mathrm{TOA}}$ (Fig. 2b) and of the aerosolinduced changes in T2m (Fig. 3a). The spatial correlation coefficient between these 2 fields is poor at only 0.24 but is statistically significant even at the $99 \%$ confidence level. Hence, the explained variance of the aerosolinduced changes in the $T 2 \mathrm{~m}$ field from the aerosol $\mathrm{RF}_{\mathrm{TOA}}$ field is only $5.8 \%$.

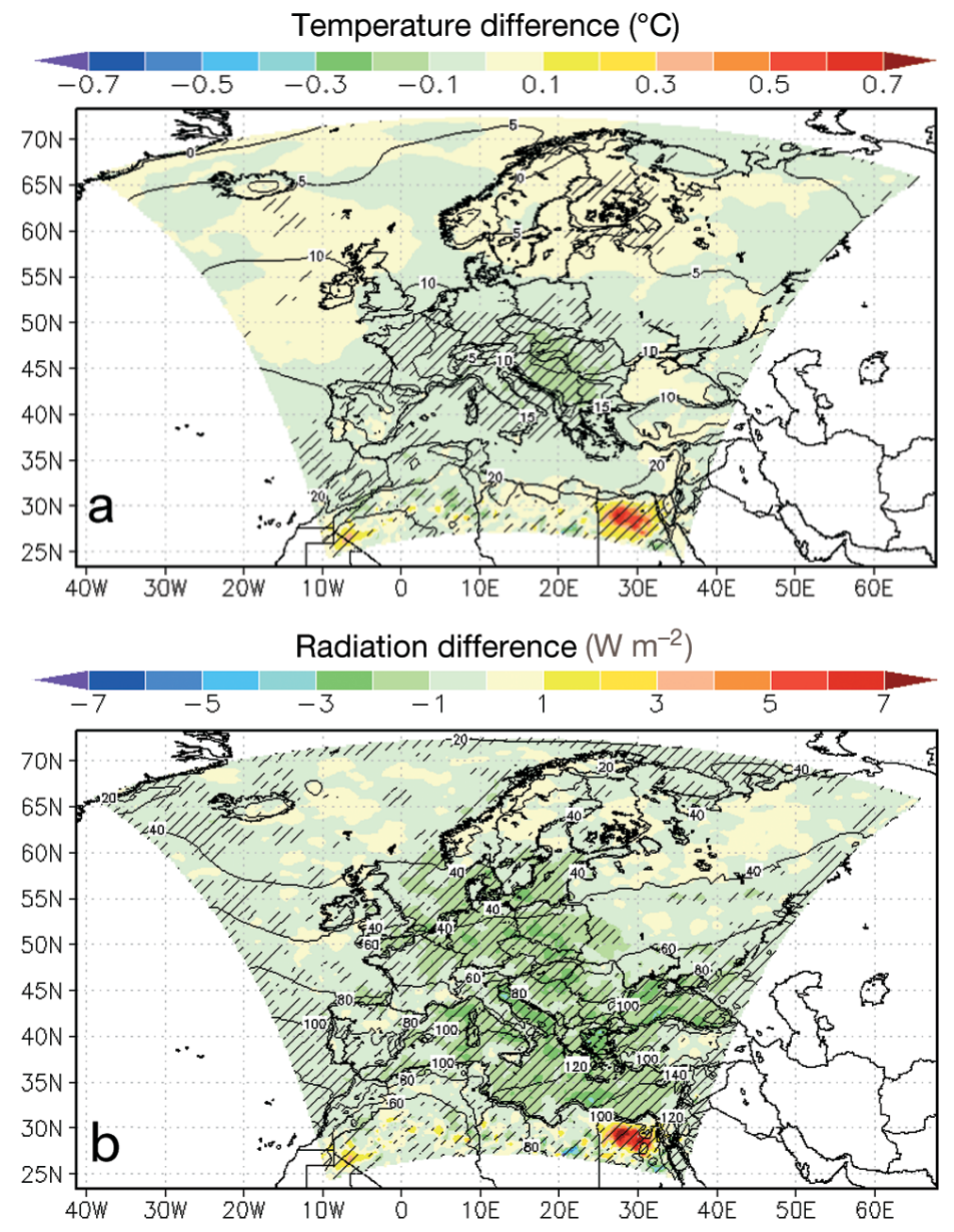

Fig. 3. Annual mean field of the difference between $\mathrm{AF}_{\text {run }}$ and $\mathrm{C}_{\text {run }}\left(\mathrm{AF}_{\text {run }}-\right.$ $\mathrm{C}_{\text {run }}$ ) (a) in near-surface air temperature at $2 \mathrm{~m}\left({ }^{\circ} \mathrm{C}\right)$ and (b) of surface net radiation budget $\left(\mathrm{W} \mathrm{m}^{-2}\right.$ ) from 1996 to 2007 (shaded). The respective mean fields of near-surface air temperature and surface net radiation budget in the control simulation $\left(\mathrm{C}_{\text {run }}\right)$ are superimposed as black contours. The line shading indicates areas in which the difference between $\mathrm{AF}_{\text {run }}$ and $\mathrm{C}_{\text {run }}$ is statistically significant at the $90 \%$ confidence level according to a 2 -tailed paired $t$-test 
Temperature difference $\left({ }^{\circ} \mathrm{C}\right)$
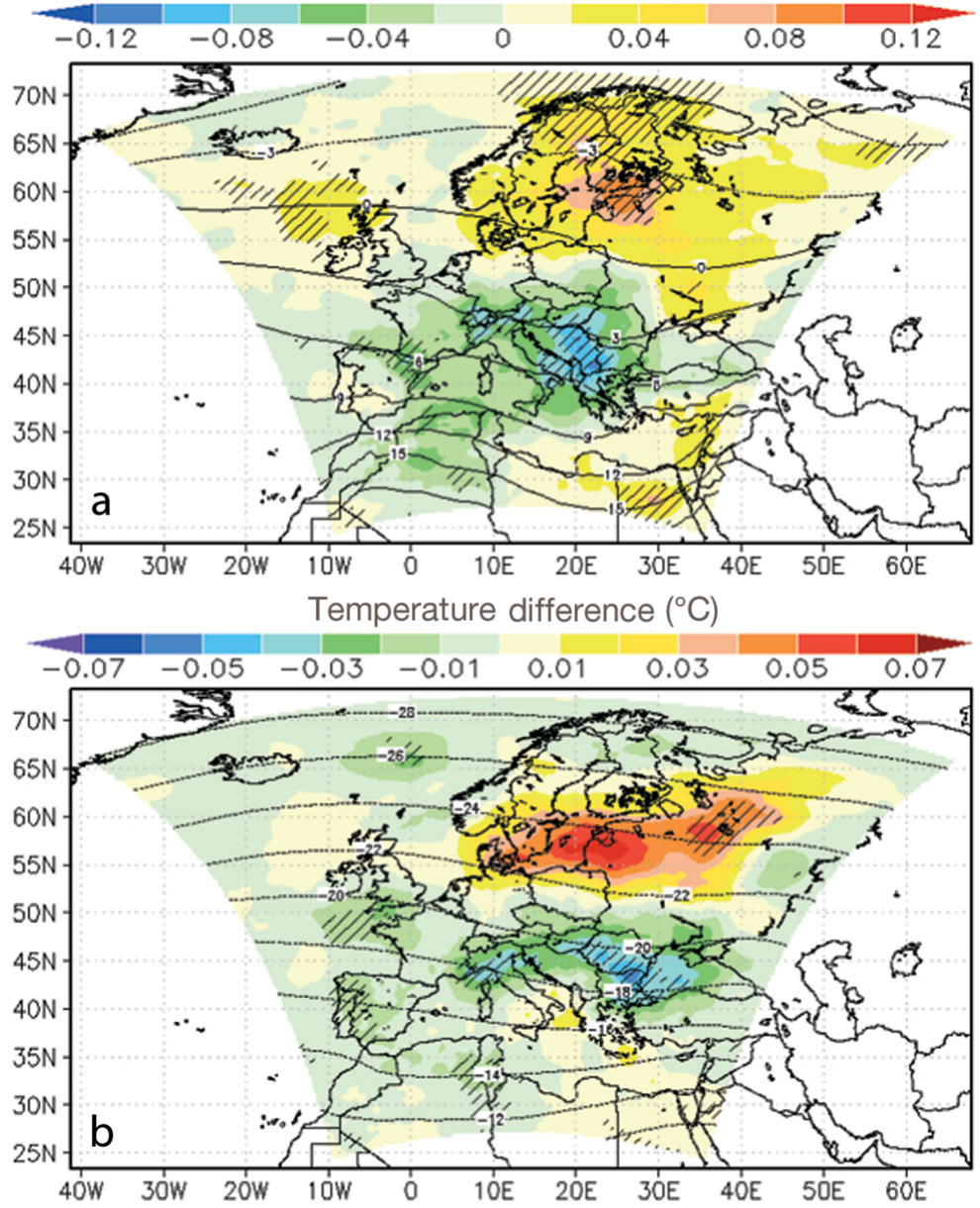

Fig. 4. Annual mean fields of the difference between $\mathrm{AF}_{\text {run }}$ and $\mathrm{C}_{\text {run }}$ $\left(\mathrm{AF}_{\text {run }}-\mathrm{C}_{\text {run }}\right)$ in air temperature $\left({ }^{\circ} \mathrm{C}\right)$ at (a) $850 \mathrm{hPa}$ and (b) $500 \mathrm{hPa}$ from 1996 to 2007 (shaded). The respective mean fields of air temperature at $850 \mathrm{hPa}$ and $500 \mathrm{hPa}$ in the control simulation $\left(\mathrm{C}_{\text {run }}\right)$ are superimposed as black contours. The line shading indicates areas in which the difference between $\mathrm{AF}_{\text {run }}$ and $\mathrm{C}_{\text {run }}$ is statistically significant at the $90 \%$ confidence level according to a 2-tailed paired $t$-test

Geopotential height difference (gpm)



plex way in which the aerosols interact with the state of the atmosphere on a regional scale, which implies there is a possible dynamical feedback of aerosols on atmospheric circulation.

Also, the aerosol-induced response in precipitation was noisy and not statistically significant in our simulations. In addition, the small changes in yearly averaged temperature for the whole period from 1996 to 2007 become greater in magnitude and variability from year to year or from month to month, indicating that the aerosols interact in a complex way with the specific atmospheric circulation patterns. In a case study from summer 2000 Zanis (2009) reported that the direct shortwave effect of anthropogenic aerosols caused a cooling of about $-1^{\circ} \mathrm{C}$ over the Balkan Peninsula.

In order to attribute the aerosol-induced changes in air temperature over Europe, the aerosol-induced changes in atmospheric circulation were investigated. A dipole pattern in aerosol-induced geopotential height changes consisting of an anticyclonic anomaly north of approx. $55^{\circ} \mathrm{N}$ and cyclonic anomaly south of approx. $45^{\circ} \mathrm{N}$ is shown in Fig. 5. This dipole pattern of changes in geopotential height corresponds well to the dipole pattern of temperature changes. This is most evident over the Balkan Peninsula where the greatest negative temperature differences are attained and the greatest strengthening of the cyclonic flow at $500 \mathrm{hPa}$ is observed. Hence, the induced cyclonic anomaly over the Balkan Peninsula may contribute to the near-surface cooling due to enhanced heat convection.

Furthermore, the geopotential height anomalies at $500 \mathrm{hPa}$ cause related changes in the wind flow at $500 \mathrm{hPa}$ (Fig. 6a). A characteristic feature in the aerosol-induced changes in the wind flow at $500 \mathrm{hPa}$ is a small decrease of the westerly zonal wind in

Fig. 5. Annual mean field of the difference between $\mathrm{AF}_{\text {run }}$ and $\mathrm{C}_{\text {run }}\left(\mathrm{AF}_{\text {run }}-\mathrm{C}_{\text {run }}\right)$ in geopotential height (gpm) at $500 \mathrm{hPa}$ from 1996 to 2007 . The respective mean field of geopotential height in the control simulation $\left(\mathrm{C}_{\text {run }}\right)$ is superimposed as black contours. The line shading indicates areas in which the difference between $\mathrm{AF}_{\text {run }}$ and $\mathrm{C}_{\text {run }}$ is statistically significant at the $90 \%$ confidence level according to a 2-tailed paired $t$-test 
Wind speed difference $\left(\mathrm{m} \mathrm{s}^{-1}\right)$
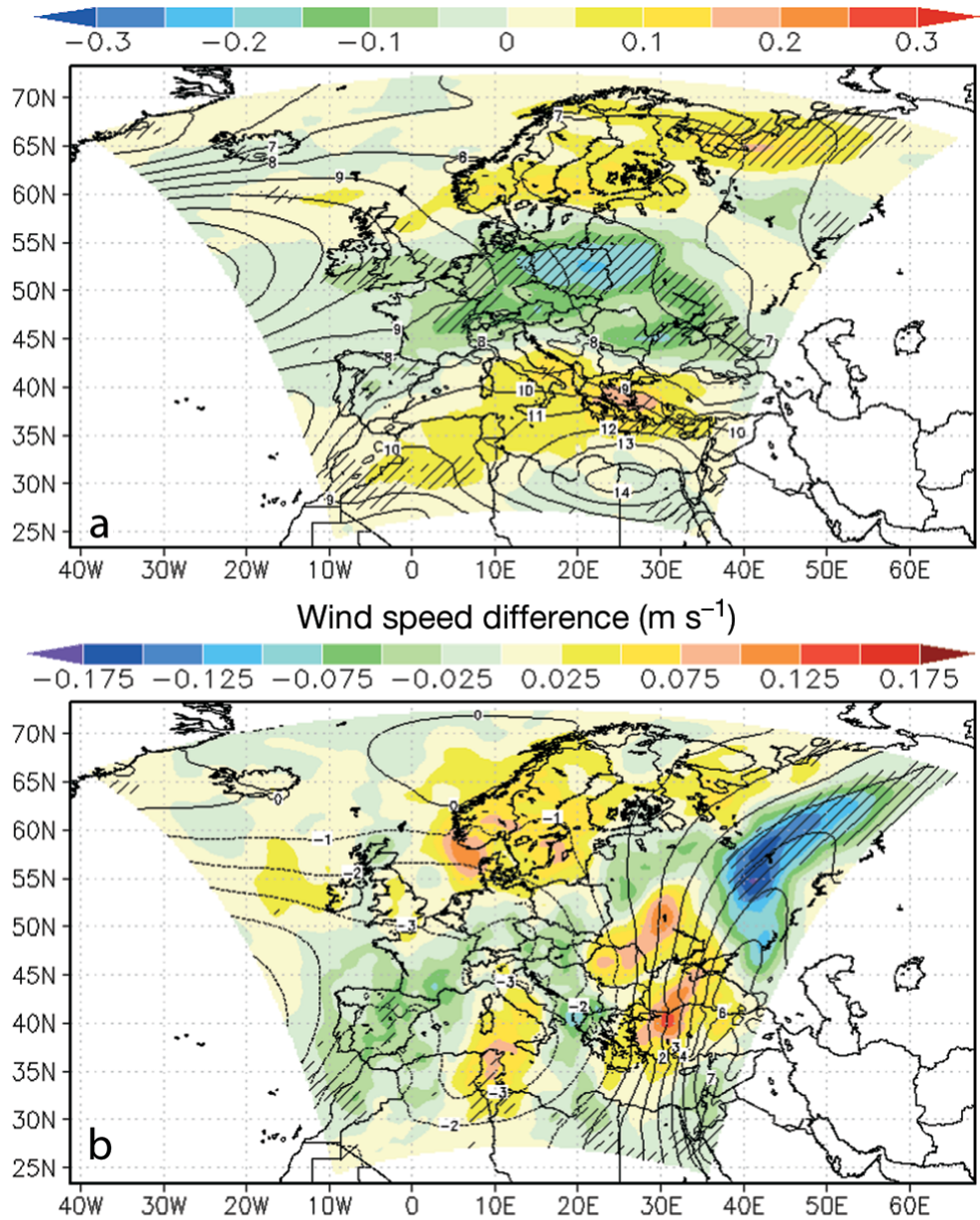

Fig. 6. Annual mean fields of the difference between $\mathrm{AF}_{\text {run }}$ and $\mathrm{C}_{\text {run }}$ $\left(\mathrm{AF}_{\text {run }}-\mathrm{C}_{\text {run }}\right)$ in (a) zonal u-wind $\left(\mathrm{m} \mathrm{s}^{-1}\right)$ and $(\mathrm{b})$ meridional v-wind $\left(\mathrm{m} \mathrm{s}^{-1}\right)$ at $500 \mathrm{hPa}$ from 1996 to 2007 . The mean fields of zonal uwind and meridional v-wind in the control simulation $\left(\mathrm{C}_{\mathrm{run}}\right)$ are superimposed as black contours. The line shading indicates areas in which the difference between $\mathrm{AF}_{\text {run }}$ and $\mathrm{C}_{\text {run }}$ is statistically significant at the $90 \%$ confidence level according to a 2-tailed paired $t$-test

the latitudinal belt between $45^{\circ}$ and $55^{\circ} \mathrm{N}$ by approx. $-0.25 \mathrm{~m} \mathrm{~s}^{-1}$ (statistically significant at the $90 \%$ confidence level), while a small increase of the zonal wind is attained northward and southward of this belt. This aerosol-induced negative anomaly of the zonal westerly wind at $500 \mathrm{hPa}$ in the latitudinal belt of 45 to $55^{\circ} \mathrm{N}$ is caused by a strengthening of an anomalous easterly flow that is consistent with a dipole pattern in geopotential heights that consists of an anticyclonic anomaly north of approx. $55^{\circ} \mathrm{N}$ and cyclonic anomaly south of approx. $45^{\circ} \mathrm{N}$. Similarly the positive anomalies of the zonal westerly wind at $500 \mathrm{hPa}$ south of approx. $40^{\circ} \mathrm{N}$ and north of approx. $60^{\circ} \mathrm{N}$ are also consistent with the northern anticyclonic and the southern cyclonic anomalies. This pattern of zonal wind changes due to aerosols is maintained in the upper troposphere as revealed by the horizontal wind changes at $250 \mathrm{hPa}$ (Fig. 7) but also with more noise in the lower troposphere (data not shown).

The aerosol-induced changes in meridional wind at $500 \mathrm{hPa}$ (Fig. 6b) shows a pattern that is consistent with the northern anticyclonic and the southern cyclonic anomalies, but the signal is not statistically significant for the largest part of Europe. Nevertheless, there is a strengthening of the northerly winds due to a negative anomaly in the meridional northerly winds (Fig. 6b) at the western side of the cyclonic anomaly over the Balkans (Fig. 5), which in turn may partially contribute to the relative cooling of the Balkan Peninsula with the advection of relatively colder air from the north.

The above results suggest that the aerosolinduced changes in atmospheric circulation play a key role in understanding the regional pattern of the aerosol-induced changes in temperature and their poor correlation with the pattern of the aerosol radiative forcing.

\section{DISCUSSION AND CONCLUSIONS}

The present work investigated the direct shortwave effect of anthropogenic aerosols on the near-surface temperatures over Europe based on simulations performed by the regional climate model RegCM3 coupled with a simplified aerosol model for the period 1996-2007. For this purpose 2 sets of 12 yr simulations were performed; the control run in which the chemical tracers only were transported and had no feedback in the radiative scheme, and one run that included the direct aerosol feedback on the shortwave radiation. The simulated AOD values were higher than the observed ones over central-eastern Europe where the sources of maximum emissions are located, which implies there is an overestimated anthropogenic aerosol radiative forcing in the model results. Furthermore, the simulated SSA values indicated the scattering role of sulphate aerosols were dominant in our model results.

Overall, the aerosol-induced changes in yearly averaged $T 2 \mathrm{~m}$ were small, ranging from -0.2 to $0.1^{\circ} \mathrm{C}$ and followed a dipole pattern in which cooling occurred south of the latitudinal zone between $50^{\circ}$ and $55^{\circ} \mathrm{N}$ and warming occurred north of $55^{\circ} \mathrm{N}$. This 
Wind speed difference $\left(\mathrm{m} \mathrm{s}^{-1}\right)$



Fig. 7. Annual mean field of the difference between $\mathrm{AF}_{\text {run }}$ and $\mathrm{C}_{\mathrm{run}}$ $\left(\mathrm{AF}_{\text {run }}-\mathrm{C}_{\text {run }}\right)$ in horizontal wind $\left(\mathrm{m} \mathrm{s}^{-1}\right)$ at $250 \mathrm{hPa}$ from 1996 to 2007. The yearly mean field of horizontal wind at $250 \mathrm{hPa}$ in the control simulation $\left(\mathrm{C}_{\text {run }}\right)$ is superimposed as black contours. The line shading indicates areas in which the difference between $\mathrm{AF}_{\text {run }}$ and $\mathrm{C}_{\text {run }}$ is statistically significant at the $90 \%$ confidence level according to a 2-tailed paired $t$-test

dipole pattern of aerosol feedback on $T 2 \mathrm{~m}$ remained in lower and middle troposphere temperatures, but the signal weakened as altitude increased. For the largest part of Europe there was a tendency for slight cooling (statistically significant at the $90 \%$ confidence level) and the greatest negative $T 2 \mathrm{~m}$ differences $\left(-0.2^{\circ} \mathrm{C}\right)$ were observed over the Balkan Peninsula. These results are in line with other regional climate studies. Ekman \& Rodhe (2003) calculated a response on $T 2 \mathrm{~m}$ that ranged between 0.1 and $-0.4^{\circ} \mathrm{C}$ due to the indirect effect on cloud albedo of anthropogenic sulphate aerosols over Europe. Vogel et al. (2009) reported for Germany a small decrease in $T 2 \mathrm{~m}$ of approx. $0.1^{\circ} \mathrm{C}$ on average for 2 case studies with cloudy and cloud-free conditions. In eastern Asia, Giorgi et al. (2002) reported that anthropogenic sulphate induced a surface cooling in the range of -0.1 to $-0.7^{\circ} \mathrm{C}$.

The field of aerosol-induced $T 2 \mathrm{~m}$ changes was not spatially collocated with the field of the aerosol $\mathrm{RF}_{\mathrm{TOA}}$ as the spatial correlation coefficient was only 0.24 and the explained variance was $5.8 \%$. Roeckner et al. (1999) also found a poor correspondence between the patterns of forcing and the temperature response in their simulations by using a coarse-resolution general circulation model (GCM). In contrast, Ekman \& Rodhe (2003) found a clear correspondence between the patterns of radiative forcing and temperature response for their high resolution simulation $\left(0.4^{\circ}\right)$, but in their simulations they accounted only for the indirect effect on cloud albedo of anthropogenic sulphate aerosols over Europe.

The dipole pattern of temperature changes corresponds well with a dipole pattern in geopotential height changes at $500 \mathrm{hPa}$ that consist of an anticyclonic anomaly north of approx. $55^{\circ} \mathrm{N}$ and cyclonic anomaly south of approx. $45^{\circ} \mathrm{N}$. These geopotential height anomalies cause related changes in the wind flow at $500 \mathrm{hPa}$ in conjunction with a small decrease in the westerly zonal wind in the latitudinal belt between $45^{\circ}$ and $55^{\circ} \mathrm{N}$ and a small increase in the zonal wind northward and southward of this belt. This pattern of zonal wind changes due to aerosols is maintained in the upper troposphere. The greatest negative lower troposphere temperature anomaly over the Balkan Peninsula is associated with the collocated greatest cyclonic anomaly with enhanced heat convection and advection of relatively colder air from the north as possible contributors to the cooling anomaly. These results indicate the role of the aerosol-induced circulation changes for the pattern of the temperature anomalies and explain the poor correlation between the patterns of aerosol-induced temperature changes and aerosol radiative forcing.

The question that arises is how the tropospheric aerosol radiative forcing can induce circulation changes from the lower to upper troposphere. It is known that the tropospheric aerosols, which are largely confined within the atmospheric boundary layer, reduce radiative flux at the surface and simultaneously scatter and absorb the solar radiation in the atmosphere, hence significantly stratifying the atmosphere and inducing important feedbacks on the surface energy budget (Yu et al. 2002). The heating anomalies imposed by the presence of the aerosols alter the thermodynamic structure of the troposphere. To maintain thermal wind balance the temperature anomalies are associated with changes in the vertical wind shear, the vertical gradient of relative vorticity and, thus, in advection. Negative lower tropospheric heating anomalies in the region of AOD maximum increase (or decrease) the meridional temperature gradient to the south (or north), leading to stronger (or weaker) vertical shear of the zonal wind. This results in the occurrence of midtropospheric anomalous zonal flow, which is in agreement with our findings. However, the exact location of the maximum temperature, wind speed and geopotential anomalies of the fields averaged over $10 \mathrm{yr}$ is the outcome of non-linear adiabatic and 
diabatic processes that can only be estimated by 3D full physics climate models, such as RegCM3, that also consider the moisture processes and the surface-atmosphere interactions over land and sea. The sequence of processes that take place in response to the anomalous radiative forcing due to the aerosols can be investigated and possibly clarified through idealized modelling.

Because the aerosol-induced changes in temperature and atmospheric circulation are at the limits of statistical significance, the present regional climate modelling study indicates there is a limited feedback on European climate related to the direct shortwave effect of European anthropogenic aerosols. The conclusion that the climate feedback of European anthropogenic aerosols is small is reached even though the AOD and the related direct radiative forcing are overestimated in our simulations. Our finding is in line with a recent study of Zubler et al. (2011b) who found that the simulated near-surface temperature trends from 1958 to 2001 in Europe were roughly unaffected by the transient aerosol emissions owing to the dominating dependence of all-sky downward surface shortwave radiation on clouds, which implies that the driving reanalysis data and prescribed SST are more important than the regionally changing aerosol emissions.

However, there are a number of limitations that should be taken into consideration for our study. One limitation is the lack of the indirect aerosol effects in cloud properties. According to IPCC (2007) the first indirect effect is comparable and can be larger than the direct aerosol effect on a global scale, while the second indirect effect is estimated to be roughly as large as the first indirect effect, but the uncertainties are also large (Lohmann \& Feichter 2005). Another limitation is that our simulations do not account for regional-to-global feedbacks at the lateral boundaries but only represent the effects of local and regional processes embedded within large-scale circulations. In a recent study Sud et al. (2009) showed that, without a 2-way feedback interaction at the boundaries of the regional domain, regional climate simulations are limited in providing reasonable assessment of the influence of large-scale aerosol anomalies on the climate. However, considering Giorgi et al. (2002), such feedbacks are most likely implicitly accounted for in the experimental setup of the present study because we used assimilated with observations large-scale fields to drive our regional model simulations. Also, only the anthropogenic emissions within Europe are considered, and hence the lateral boundaries are restricted from advection of aerosols from outside. Furthermore, our emissions did not account for other anthropogenic aerosols such as nitrates, ammonium and secondary organic and mineral dust of industrial origin as well as naturally emitted aerosols, including biogenic particles, dust, sea salt and forest fire particles, that may play an important role on a regional scale (Kanakidou et al. 2005, IPCC 2007, Solmon et al. 2008, Zakey et al. 2008, Raes et al. 2010).

Finally, the internal model variability is a factor that should be also considered in the design, analysis and interpretation of RCM experiments, especially in RCM sensitivity studies that examine small changes in forcing (Giorgi \& Bi 2000, O'Brien et al. 2011). Direct interpretation of anomalies from RCM sensitivity studies relies on the assumption that differences between model simulations are entirely due to a physical forcing. However, if a model's internal variability is as large as or larger than the physical signal, then this assumption is violated. The model's internal variability arises from the chaotic sensitivity to initial and lateral boundary conditions. O'Brien et al. (2011) suggested that the model's internal variability can be reduced by generating ensembles of simulations since owing to its random nature the variability should tend toward zero as the number of ensemble members increases. In our sensitivity experiment, which only had 2 sets of a 12 yr simulation, we integrated the model results on an annual basis to reduce the noise from the model's internal variability.

Acknowledgements. We thank the 3 anonymous reviewers for their constructive comments.

\section{LITERATURE CITED}

Bäumer D, Vogel B (2007) An unexpected pattern of distinct weekly periodicities in climatological variables in Germany. Geophys Res Lett 34:L03819. doi:10.1029/ 2006GL028559

Chung SH, Seinfeld JH (2002) Global distribution and climate forcing of carbonaceous aerosols. J Geophys Res 107:4407. doi:10.1029/2001JD001397

> Cooke WF, Liousse C, Cachier H, Feichter J (1999) Construction of a $1^{\circ} \times 1^{\circ}$ fossil fuel emission data set for carbonaceous aerosol and implementation and radiative impact in the ECHAM4 model. J Geophys Res 104: 22137-22162

Cooke WF, Ramaswamy V, Kasibhatla P (2002) A general circulation model study of the global carbonaceous aerosol distribution. J Geophys Res 107:4279. doi:10.1029/ 2001JD001274

Dickinson R, Henderson-Sellers A, Kennedy PJ (1993) Biosphere-Atmosphere Transfer Scheme, BATS: version1E as coupled to the NCAR community climate model. NCAR Tech Note NCAR/TN-387+STR. National Center for Atmospheric Research, Boulder, CO 
Ekman AML, Rodhe H (2003) Regional temperature response due to indirect sulfate aerosol forcing: impact of model resolution. Clim Dyn 21:1-10

Fritsch JM, Chappell CF (1980) Numerical prediction of convectively driven mesoscale pressure systems. Part I: convective parameterization. J Atmos Sci 37:1722-1733

Ghan SJ, Schwartz SE (2007) Aerosol properties and processes: a path from field and laboratory measurements to global climate models. Bull Am Meteorol Soc 88: 1059-1083

Giorgi F, Bi X (2000) A study of internal variability of a regional climate model. J Geophys Res 105:29503-29521

Giorgi F, Bi X, Qian Y (2002) Direct radiative forcing and regional climatic effects of anthropogenic aerosols over East Asia: a regional coupled climate-chemistry/aerosol model study. J Geophys Res 107:4439. doi:10.1029/2001 JD001066

> Giorgi F, Bi X, Qian Y (2003) Indirect versus direct effects of anthropogenic sulfate on the climate of east Asia as simulated with a regional coupled climate-chemistry/ aerosol model. Clim Change 58:345-376

> Giorgi F, Pal JS, Bi X, Sloan L, Elguindi N, Solmon F (2006) Introduction to the TAC special issue: the RegCNET network. Theor Appl Climatol 86:1-4

- Grell GA (1993) Prognostic evaluation of assumptions used by cumulus parametrizations. Mon Weather Rev 121: 764-787

Grell GA, Dudhia J, Stauer DR (1994) A description of the fifth-generation Penn State/NCAR mesoscale model (mm5). Tech Rep NCAR/TN-398+STR, National Center for Atmospheric Research, Boulder, CO

> Hansen J, Sato M, Ruedy R (1997) Radiative forcing and climate response. J Geophys Res 102(D6):6831-6864

Huszar P, Miksovsky J, Pisoft P, Belda M, Halenka T (2012) Interactive coupling of a regional climate model and a chemical transport model: evaluation and preliminary results on ozone and aerosol feedback. Clim Res 51: $59-88$

IPCC (Intergovernmental Panel on Climate Change) (2007) Climate change: the physical science basis. Contribution of Working Group I to the 4th Assessment Report of the Intergovernmental Panel on Climate Change. Cambridge University Press, Cambridge

Jacobson MZ (2001) Global direct radiative forcing due to multicomponent anthropogenic and natural aerosols. J Geophys Res 106:1551-1568

Johnson BT, Shine KP, Forster PM (2004) The semi-direct aerosol effect: impact of absorbing aerosols on marine stratocumulus. Q J R Meteorol Soc 130:1407-1422

Kanakidou M, Seinfeld JH, Pandis SN, Barnes I and others (2005) Organic aerosol and global climate modelling: a review. Atmos Chem Phys 5:1053-1123

Kanamitsu M, Ebisuzaki W, Woollen J, Yang SK, Hnilo JJ, Fiorino M, Potter GL (2002) NCEP-DOE AMIP-II reanalysis (R-2). Bull Am Meteorol Soc 83:1631-1643

Kasibhatla P, Chameides WL, St. John J (1997) A threedimensional global model investigation of seasonal variation in the atmospheric burden of anthropogenic sulfate aerosols. J Geophys Res 102:3737-3759

Kasten F (1969) Visibility in the prephase of condensation. Tellus 21:631-635

Kiehl JT, Hack JJ, Bonan GB, Boville BA, Breigleb BP, Williamson D, Rasch P (1996) Description of the NCAR community climate model (ccm3). Tech Rep NCAR/TN420+STR. National Center for Atmospheric Research, Boulder, CO

Kiehl JT, Schneider TL, Rasch PJ, Barth MC, Wong J (2000) Radiative forcing due to sulfate aerosols from simulations with the National Center for Atmospheric Research community climate model version 3. J Geophys Res 105:
1441-1457

Levy RC, Remer LA, Kleidman RG, Mattoo S, Ichoku C, Kahn R, Eck TF (2010) Global evaluation of the Collection 5 MODIS dark-target aerosol products over land. Atmos Chem Phys 10:10399-10420

Li F, Vogelmann AA, Ramanathan V (2004) Saharan dust aerosol radiative forcing measured from space. J Clim $17: 2558-2571$

Lohmann U, Feichter J (2001) Can the direct and semi-direct aerosol effect compete with the indirect effect on a global scale? Geophys Res Lett 28:159-161

Lohmann U, Feichter J (2005) Global indirect aerosol effects: a review. Atmos Chem Phys 5:715-737

Mätzler C (2002) MATLAB functions for Mie scattering and absorption. IAP Res Rep No 02-08. Institute of Applied Physics, University of Bern

Menon S, Hansen J, Nazarenko L, Luo Y (2002) Climate effects of black carbon aerosols in China and India. Science 297:2250-2253

> O'Brien TA, Sloan LC, Snyder MA (2011) Can ensembles of regional climate model simulations improve results from sensitivity studies? Clim Dyn 37:1111-1118

Pal JS, Small EE, Eltahir EAB (2000) Simulation of regionalscale water and energy budgets: representation of subgrid cloud and precipitation processes within RegCM. J Geophys Res 105:29579-29594

> Pal JS, Giorgi F, Bi X, Elguindi N and others (2007) Regional climate modeling for the developing world: the ICTP RegCM3 and RegCNET. Bull Am Meteorol Soc 88: 1395-1409

> Papadimas CD, Hatzianastassiou N, Mihalopoulos N, Kanakidou M, Katsoulis BD, Vardavas I (2009) Assessment of the MODIS Collections C005 and C004 aerosol optical depth products over the Mediterranean basin. Atmos Chem Phys 9:2987-2999

Qian Y, Giorgi F, Huang Y (2001) Regional simulation of anthropogenic sulfur over east Asia and its sensitivity to model parameters. Tellus 53:171-191

Qian Y, Leung LR, Ghan SJ, Giorgi F (2003) Regional climate effects of aerosols over China: modeling and observations. Tellus 55B:914-934

Raes F, Liao H, Chen WT, Seinfeld JH (2010) Atmospheric chemistry-climate feedbacks. J Geophys Res 115: D12121. doi:10.1029/2009JD013300

Ramanathan V, Feng Y (2009) Air pollution, greenhouse gases and climate change: global and regional perspectives. Atmos Environ 43:37-50

Ramanathan V, Crutzen PJ, Kiehl JT, Rosenfeld D (2001) Aerosols, climate, and the hydrological cycle. Science 294:2119-2124

Rauscher SA, Coppola E, Piani C, Giorgi F (2010) Resolution effects on regional climate model simulations of seasonal precipitation over Europe. Clim Dyn 35:685-711

Reddy MS, Boucher O (2004) A study of the global cycle of carbonaceous aerosols in the LMDZT general circulation model. J Geophys Res 109:D14202. doi:10.1029/2003 JD004048

Roeckner E, Bengtsson L, Feichter J, Lelievelds J, Rodhe H (1999) Transient climate change simulations with a coupled atmosphere-ocean GCM including the tropospheric sulfur cycle. J Clim 12:3004-3032

Sanchez-Gomez E, Somot S, Déqué M (2009) Ability of an ensemble of regional climate models to reproduce weather regimes over Europe-Atlantic during the period 1961-2000. Clim Dyn 33:723-736

Solmon F, Giorgi F, Liousse C (2006) Aerosol modelling for regional climate studies: application to anthropogenic particles and evaluation over a European/African domain. Tellus 58B:51-72

Solmon F, Mallet M, Elguindi N, Giorgi F, Zakey A, Konare 
A (2008) Dust aerosol impact on regional precipitation over western Africa, mechanisms and sensitivity to absorption properties. Geophys Res Lett 35:L24705. doi: 10.1029/2008GL035900

Sud YC, Lau WKM, Wilcox E, Walker GK and others (2009) Sensitivity of boreal-summer circulation and precipitation to atmospheric aerosols in selected regions - Part I: Africa and India. Ann Geophys 27:3989-4007

Takemura T, Nakajima T, Dubovik O, Holben BN, Kinne S (2002) Single-scattering albedo and radiative forcing of various aerosol species with a global three-dimensional model. J Clim 15:333-352

Tombette M, Chazette P, Sportisse B, Roustan Y (2008) Simulation of aerosol optical properties over Europe with a 3-D size-resolved aerosol model: comparisons with AERONET data. Atmos Chem Phys 8:7115-7132

Vogel B, Vogel H, Bäumer D, Bangert M, Lundgren K, Rinke R, Stanelle T (2009) The comprehensive model system COSMO-ART - radiative impact of aerosol on the state of the atmosphere on the regional scale. Atmos Chem Phys 9:8661-8680

Submitted: February 28, 2011; Accepted: November 22, 2011
Yu H, Liu SC, Dickinson RE (2002) Radiative effects of aerosols on the evolution of the atmospheric boundary layer. J Geophys Res 107:4142. doi:10.1029/2001JD 000754

Zakey AS, Giorgi F, Bi X (2008) Modeling of sea salt in a regional climate model: fluxes and radiative forcing. J Geophys Res 113:D14221. doi:10.1029/2007JD 009209

Zanis P (2009) A study on the direct effect of anthropogenic aerosols on near surface temperature over Southeastern Europe during summer 2000 based on regional climate modelling. Ann Geophys 27:3977-3988

Zubler EM, Folini D, Lohmann U, Lüthi D and others (2011a) Implementation and evaluation of aerosol and cloud microphysics in a regional climate model. J Geophys Res 116:D02211. doi:10.1029/2010JD014572

Zubler EM, Folini D, Lohmann U, Lüthi D, Schär C, Wild M (2011b) Simulation of dimming and brightening in Europe from 1958 to 2001 using a regional climate model. J Geophys Res 116:D18205. doi:10.1029/2010JD 015396

Proofs received from author(s): February 23, 2012 